\title{
Predictors of pain in general ageing populations: results from a multi-country analysis based on ATHLOS harmonized database
}

\author{
Alberto Raggi ${ }^{1}$, Matilde Leonardi i* ${ }^{*}$, Blanca Mellor-Marsá2 ${ }^{2}$ Maria V. Moneta ${ }^{2}$, Albert Sanchez-Niubo ${ }^{2,3}$, \\ Stefanos Tyrovolas ${ }^{2,3,4}$, lago Giné-Vázquez ${ }^{2,3}$, Josep M. Haro ${ }^{2,3}$, Somnath Chatterji ${ }^{5}$, Martin Bobak ${ }^{6}$, \\ Jose L. Ayuso-Mateos ${ }^{3,7,8}$, Holger Arndt ${ }^{9}$, Muhammad Z. Hossin ${ }^{10}$, Jerome Bickenbach ${ }^{11,12}$, Seppo Koskinen ${ }^{13}$, \\ Beata Tobiasz-Adamczyk ${ }^{14}$, Demosthenes Panagiotakos ${ }^{4}$ and Barbara Corso ${ }^{15}$
}

\begin{abstract}
Background: Pain is a common symptom, often associated with neurological and musculoskeletal conditions, and experienced especially by females and by older people, and with increasing trends in general populations. Different risk factors for pain have been identified, but generally from studies with limited samples and a limited number of candidate predictors. The aim of this study is to evaluate the predictors of pain from a large set of variables and respondents.
\end{abstract}

Methods: We used part of the harmonized dataset of ATHLOS project, selecting studies and waves with a longitudinal course, and in which pain was absent at baseline and with no missing at follow-up. Predictors were selected based on missing distribution and univariable association with pain, and were selected from the following domains: Sociodemographic and economic characteristics, Lifestyle and health behaviours, Health status and functional limitations, Diseases, Physical measures, Cognition, personality and other psychological measures, and Social environment. Hierarchical logistic regression models were then applied to identify significant predictors.

Results: A total of 13,545 subjects were included of whom 5348 (39.5\%) developed pain between baseline and the average 5.2 years' follow-up. Baseline risk factors for pain were female gender (OR 1.34), engaging in vigorous exercise (OR 2.51), being obese (OR 1.36) and suffering from the loss of a close person (OR 1.88) whereas follow-up risk factors were low energy levels/fatigue (1.93), difficulties with walking (1.69), self-rated health referred as poor (OR 2.20) or average to moderate (OR 1.57) and presence of sleep problems (1.80).

(Continued on next page)

\footnotetext{
* Correspondence: matilde.leonardi@istituto-besta.it

${ }^{1}$ Neurology, Public Health and Disability Unit, Fondazione IRCCS Istituto

Neurologico Carlo Besta, Via Celoria 11, 20133 Milan, Italy

Full list of author information is available at the end of the article
}

C C The Author(s). 2020 Open Access This article is licensed under a Creative Commons Attribution 4.0 International License, which permits use, sharing, adaptation, distribution and reproduction in any medium or format, as long as you give appropriate credit to the original author(s) and the source, provide a link to the Creative Commons licence, and indicate if changes were made. The images or other third party material in this article are included in the article's Creative Commons licence, unless indicated otherwise in a credit line to the material. If material is not included in the article's Creative Commons licence and your intended use is not permitted by statutory regulation or exceeds the permitted use, you will need to obtain permission directly from the copyright holder. To view a copy of this licence, visit http://creativecommons.org/licenses/by/4.0/. The Creative Commons Public Domain Dedication waiver (http://creativecommons.org/publicdomain/zero/1.0/) applies to the data made available in this article, unless otherwise stated in a credit line to the data. 
(Continued from previous page)

Conclusions: Our results showed that $39.5 \%$ of respondents developed pain over a five-year follow-up period, that there are proximal and distal risk factors for pain, and that part of them are directly modifiable. Actions aimed at improving sleep, reducing weight among obese people and treating fatigue would positively impact on pain onset, and avoiding vigorous exercise should be advised to people aged 60 or over, in particular if female or obese.

Keywords: Pain, Risk factors, Headache disorders, Musculoskeletal disorders, Sleep, Obesity, Exercise, Bereavement, Fatigue, Walking

\section{Introduction}

Pain is one of the most common symptoms in general populations and is the core symptom of many common, and often comorbid, clinical conditions. In fact, the prevalence of pain-associated conditions is between $10 \%$ and $60 \%$ approximately, with the highest rates being observed for tension-type headache [1-11]. Data referred to general populations are on the contrary almost lacking. A recent study from the U.S. showed that the overall rates of noncancer pain prevalence increased from $32.9 \%$ to $41.0 \%$ over an 18-years period (1997-98 to 2013-14) [12]. Such an information was confirmed in a recent study based on the harmonized dataset generated by ATHLOS project (Ageing Trajectories of Health - Longitudinal Opportunities and Synergies) [13]. Such a recent paper showed that pain rates largely vary by sex, participants' age, period of inclusion in the studies and birth cohort [14]. In particular, pain rates were shown to vary between 20 and 30\% in males enrolled in the early 1990s, and 60-70\% among old-age women enrolled between 2011 and 2015. In addition to this, the 10-years forecast suggested an increase in the trends of pain which will peak up to $20 \%$ among females and among older subjects [14].

Given the observed and predicted increase of pain rates, determinants need to be addressed in order to limit to the widest extent the possible negative consequences of such an expansion, for example the risk of future opioids and other drugs' overuse, increase in disability, reduction in quality of life and employment rates, and productivity loss [15-25]. A large amount of studies identified potential predictors of pain, both in clinical trials and in population or cohort studies. Among population and cohort studies, evidence existed on the impact of sociodemographic characteristics, with females [2633 ] and older people [6, 27, 28, 31, 32, 34] reporting higher pain rates or severity. Also, people with lower education level and those unemployed had higher pain rates $[35,36]$, but contrasting results were found with reference to socioeconomic position: in fact, Chen and colleagues found that people with a lower socioeconomic class had a more severe trajectory with regard to low back pain severity and persistence [37], whereas Elsharydah and colleagues found that higher median household income was associated with higher rate of complex regional pain syndrome type 1 [30]. Evidence was also found on the impact of some mental health problems and symptoms on pain rates and severity, including sleep problems [6, 27, 34, 38, 39], depressed mood or anxiety [26, 28-30, 34, 35, 39, 40], cognitive complaints [34] and fatigue or lack of energy [38]. Other health status variables that were found to be associated with higher pain rates and severity included the presence of comorbidities and multimorbidity status $[6,26,30,35,39,41]$ and, among single heath conditions, diabetes and stroke [30, 42, 43]: of course, presence of conditions whose cardinal symptom is pain, such as headaches, musculoskeletal conditions or angina, is clearly acknowledged to impact on pain. Finally, a set of risk and protective lifestyle factors were also identified. Physical activity was found to be protective against back pain onset among older adult women [29], smoking was found to be a risk factor for the development of chronic musculoskeletal pain [44], and high body mass index (BMI) or obesity status were risk factors for higher pain rates, development of musculoskeletal conditions and pain worsening [6, 27, 29, 30, 33, 35, 45, 46].

The information herein available is however limited to specific cohorts, such as military or farmers, or cohort of patients, with population studies presenting a limited amount of pain predictors, a relatively limited amount of participants, with different ages and a limited geographical distribution. This provides a partial appreciation of global pain predictors, which can be on the contrary achieved through an analysis of a large dataset such as that of ATHLOS project, where data from 17 different population survey conducted in the five continents were harmonized [13]. This paper aims to provide the most comprehensive identification of pain predictors in ageing populations.

\section{Methods}

\section{Study population}

The last available wave of each study (i.e. harmonized in the ATHLOS project) was defined as follow-up wave, while the baseline wave was selected trying to keep, when possible, one wave in between the two. The baseline wave did not necessarily coincide with study's baseline wave. 
The studies and waves selected for the present analyses were: the China Health and Retirement Longitudinal Study (CHARLS: W1-W2), the Collaborative Research on Ageing in Europe (COURAGE in Europe: W1-W2), the Health and Retirement Study (HRS: W9W11), the Health 2000/2011 study (W1-W2), the Mexican Health and Aging Study (MHAS: W2-W3), and the Survey of Health, Ageing and Retirement in Europe (SHARE: W4-W5). On average, the follow-up waves were carried out 5.2 (SD 3.2) years after the baseline waves (see Table S1 in supplementary materials for pain variable distribution and follow-up duration in the different studies).

\section{Variables of interest}

The outcome variable was the absence/presence of the harmonized pain variable (defined as "self-reported pain experienced at the time of the interview") at follow-up. Absence of pain was defined as absence of pain at both baseline and follow-up wave, while presence of pain was identified as absence of pain at baseline but presence of pain at follow-up. In total, 91,278 subjects did not report pain at baseline and, of them, 50,849 had complete data on pain at follow-up: of them 36,023 still did not report pain, whereas 14,826 (29.2\%) reported pain.

Candidate predictors of pain were selected from the different domains defined in the ATHLOS harmonization. Domain "Lifestyle and health behaviours": current smoking status, current alcohol use and engagement in vigorous exercise; "Health status and functional limitations": level of energy, sleep quality, mobility walk, self-reported health, presence of recent falls and evaluative wellbeing; "Diseases": diabetes, respiratory disease, hypertension, joint disorders, angina, stroke, cancer and multimorbidity; "Physical measures": obesity; "Cognition, personality and other psychological measures": depression; "Social environment": bereavement, i.e. the experience of a loss of any close person. Moreover, in the domain "Socio-demographic and economic characteristics", gender, marital status, education, retirement status and wealth quintile of participants were retrieved. All these variables were selected from both baseline and follow-up waves (see Table S2 in supplementary materials for the definition of harmonized variables).

\section{Data analysis}

Initially, as a screening criterion, we excluded variables with a relevant amount of missing that would have dramatically reduced the sample size exploitable for the present analysis. Second, predictors of pain were assessed using univariable logistic regression models and those with a $p$-value $<0.10$ were retained in the subsequent analyses (see Table S2 in supplementary materials).
Next, two stepwise forward logistic regressions were performed (the $p$-value for variable inclusion and removal were set to $p<0.05$ and $p<0.15$, respectively). The first stepwise was performed with baseline variables only as predictors of pain development at follow-up, and later a multivariable logistic regression was implemented retaining only statistically significant predictors $(p<$ 0.05). Then, in the second stepwise, the significant predictors identified at baseline were kept in the model and follow-up variables were included for selection. Lastly, a final model was pursued with only significant predictors at both baseline and follow-up. All models were weighted and adjusted for a time-lag variable (defined as the difference between the year of interview at follow-up and baseline). Multicollinearity was checked using tolerance and Variance Inflation Factor (VIF): variables with tolerance $<0.4$ (VIF $>2.5)$ were discarded from the analysis. Engagement in vigorous exercise at follow-up was discarded form the analyses due to collinearity. Models' goodness-of-fit were assessed by the Hosmer and Lemeshow's test and by visual inspection of the plot of estimated values against residuals, whilst specification error was evaluated by running a new regression with the observed values against predicted and predicted-squared values as independent variables. The Area Under the Receiver Operating Curve (AUC) and its 95\% confidence interval $(95 \% \mathrm{CI})$ for the predicted versus the actual data was also calculated. Categorical variables were reported as proportions, and continuous variables were reported as means \pm standard deviations (SD) and medians with interquartile ranges (IQRs). Odds ratios (ORs) were presented with their $95 \% \mathrm{CI}$ and $\mathrm{Z}$ with its associated $p$ value. All statistical analyses were performed using STATA SE, version 15.0 (Stata Statistical Software: Release 12. College Station, TX: StataCorp LP).

\section{Results}

Almost all variables, at both baseline and follow-up, were significant predictors of pain in univariable regression models (see Table S2 in supplementary materials): the exceptions to this were being single (vs. married) at baseline and being retired (vs. employed or student) at follow-up.

Stepwise regression with baseline variables enabled retaining eight predictors (gender, sleep problems, engagement in vigorous exercise, bereavement, obesity, self-rated health, multimorbidity and smoking), and follow-up variables enabled retaining seven predictors (energy level, difficulties with walking, respiratory diseases, joint disorders, stroke and again self-rated health and sleep problems). The full results of multivariable regression models are in supplementary materials (see Table S3). The final sample size was composed of 13,545 subjects, 8197 without pain and 5348 that 
developed pain between baseline and follow-up, corresponding to $39.5 \%$ of the sample.

Table 1 provides full features of the final sample. Females represented $53.3 \%$ of the entire sample, and average age moved from a median of 63 to a median of 68 years, and more than one-third of the sample was retired. Most descriptive variables were almost similar at the two time points, with some exceptions: for example, difficulty walking increased from $9.7 \%$ to $18.7 \%$, and poor self-reported health from $5.1 \%$ to $8.9 \%$. Among health conditions, hypertension and joint disorders were the two most common at baseline $(37.4 \%$ and $26.6 \%$, respectively) and underwent a significant increase $(51.6 \%$ and $38.6 \%$ at follow-up, respectively), and multimorbidity was experienced by $27.3 \%$ of participants at baseline and $40.1 \%$ at follow-up. The same data are reported study by study in supplementary materials (see Tables S4, S5, S6, S7, S8, S9).

Table 2 reports the results of the following models: Model 1, stepwise-selected baseline predictors; Model 2, significant baseline predictors only $(p<0.05)$; Model 3 , significant baseline predictors and stepwise-selected follow-up predictors. All baseline variables, with the exclusion of smoking status and multimorbidity, were significant risk factors for pain at 5.2 years' follow-up. Once variables selected at follow-up were included, baseline self-rated health was no more significant, whereas the corresponding follow-up variable was. Among newly included variables, low-level energy/fatigue, difficulties with walking, sleep problems and respiratory disease were significant risk factors for pain occurrence, whereas neither joint disorders nor stroke were significant predictors.

Table 3 shows the results of the final model, where significant predictors only were retained. Being female, engaging in vigorous exercise, being obese and bereavement were all risk factors for the onset of pain over an average period of 5.2 years. In addition to this, low energy levels, difficulties with walking, non-good self-rated health and presence of sleep problems were significant risk factors for the presence of pain at the follow up.

\section{Discussion}

The results of this study, based on a large sample of general ageing population, showed that $39.5 \%$ of respondents developed pain over a five-year follow-up period and that there are proximal and distal risk factors for pain. Proximal risk factors include low energy level (or fatigue), walking difficulties, self-rated health perceived as not good and sleep problems, whereas distal risk factors - which predicted pain onset over a five-year timeframe - included female gender, engaging in vigorous exercise, being obese and suffering from the loss of a close person. It is interesting to notice that two risk factors, namely sleep problems and poorer self-rated health were retained among distal ones, but they were discarded from the final model once proximal risk factors were included.

What makes our results of such an importance is that most of the risk factors herein included are modifiable, either directly or indirectly. Factors that may be directly addressed include sleep problems, obesity, engagement in vigorous activities, low energy/fatigue and walking difficulties, whereas factors such as self-rated health can be targeted through general health improvement interventions, as well as through interventions aimed to address some of the aforementioned targets, such as sleep improvement and weight loss. In addition to this, we did not include age as a variable in our analysis, but decided to include the ageing process itself, by weighting and adjusting all our models for a time-lag variable, i.e. the years passing between the two time points in each study.

Sleep problems may impact on pain in different ways, and are part of common associated symptomatology in different pain-related conditions affecting adults and older adults, such as low back pain, headache disorders or osteoarthritis [47-49]. As reported in a recent review [50] several hypotheses have been made. Disrupted sleep continuity (i.e. wakefulness during the night) may contribute to increased pain perception (and higher opioids consumption) through disruption of opioid circuits involved in the descending pain modulatory systems, and involvement of inflammatory mechanisms typical of ageing-related conditions such as cardiovascular disorders, hypertension and diabetes, has also been addressed. In fact, sleep disturbance were associated with increases in markers of systemic inflammation, such as interleukin-6, which is known to sensitize nociceptors and increase pain sensitivity [51]. It has to be acknowledged that insomnia and reduced sleep hours are part of the ageing process itself, with older people having difficulty falling and staying asleep due to frequent arousals [52]. Treatments are both pharmacological and nonpharmacological [53-55]: among the first, benzodiazepines, sedating low-dose antidepressants, antipsychotics and anticonvulsants are included, whereas nonpharmacological treatments mostly include cognitive behavioural therapy. There is a growing interest on behavioural treatment for sleep disturbances in older adults and elderlies, mostly in reason of their reduced risks and hazards of sedative-hypnotics and opioids for middleaged and older adults, as well as in consideration of the interaction between drugs prescribed for sleep problems and those for other medical conditions [51, 53].

Obesity is another known factor contributing to pain, through both inflammatory and mechanical processes $[56,57]$. Obesity is in fact a pro-inflammatory condition and literature exists on the role of proinflammatory 
Table 1 Final regression model sample description

\begin{tabular}{|c|c|c|c|c|c|c|}
\hline & \multicolumn{3}{|l|}{ Baseline } & \multicolumn{3}{|l|}{ Follow-up } \\
\hline & $\begin{array}{l}\text { No pain at } \\
\text { follow-up } \\
(N=8197)\end{array}$ & $\begin{array}{l}\text { Pain at } \\
\text { follow-up } \\
(N=5348)\end{array}$ & $\begin{array}{l}\text { Total } \\
(N=13,545)\end{array}$ & $\begin{array}{l}\text { No pain at } \\
\text { follow-up } \\
(N=8197)\end{array}$ & $\begin{array}{l}\text { Pain at follow-up } \\
(N=5348)\end{array}$ & $\begin{array}{l}\text { Total } \\
(N=13,545)\end{array}$ \\
\hline $\begin{array}{l}\text { Age, mean } \pm \text { sd } \\
\text { [median: interquartile range] }\end{array}$ & $\begin{array}{l}59.8 \pm 14.4 \\
{[64: 52-71]}\end{array}$ & $\begin{array}{l}60.62 \pm 13.0 \\
{[62: 53-70]}\end{array}$ & $\begin{array}{l}60.1 \pm 13.9 \\
{[63: 53-70]}\end{array}$ & $\begin{array}{l}65.5 \pm 13.9 \\
{[70: 59-75]}\end{array}$ & $\begin{array}{l}64.9 \pm 12.6 \\
{[66: 57-74]}\end{array}$ & $\begin{array}{l}65.3 \pm 13.5 \\
{[68: 57-75]}\end{array}$ \\
\hline Sex & & & $(N=13,545)$ & & & $(N=13,545)$ \\
\hline Male & $49.8 \%$ & $41.9 \%$ & $46.7 \%$ & $49.8 \%$ & $41.9 \%$ & $46.7 \%$ \\
\hline Female & $50.2 \%$ & $58.1 \%$ & $53.3 \%$ & $50.2 \%$ & $58.1 \%$ & $53.3 \%$ \\
\hline Marital status & & & $(N=13,529)$ & & & $(N=13,526)$ \\
\hline Married/cohabiting & $71.1 \%$ & $71.4 \%$ & $71.2 \%$ & $67.2 \%$ & $67.2 \%$ & $67.2 \%$ \\
\hline Single & $8.3 \%$ & $8.0 \%$ & $8.2 \%$ & $7.5 \%$ & $7.8 \%$ & $7.6 \%$ \\
\hline Divorced/Separated & $7.1 \%$ & $7.1 \%$ & $7.1 \%$ & $7.7 \%$ & $7.3 \%$ & $7.6 \%$ \\
\hline Widow & $13.5 \%$ & $13.5 \%$ & $13.5 \%$ & $17.6 \%$ & $17.7 \%$ & $17.6 \%$ \\
\hline Education & & & $(N=11,384)$ & & & $(N=9931)$ \\
\hline Primary or less & $28.6 \%$ & $38.3 \%$ & $32.5 \%$ & $20.3 \%$ & $31.6 \%$ & $24.9 \%$ \\
\hline Secondary or above & $71.4 \%$ & $61.7 \%$ & $67.5 \%$ & $79.7 \%$ & $68.4 \%$ & $75.1 \%$ \\
\hline \multirow[t]{2}{*}{ Retired } & & & $(N=12,984)$ & & & $(N=12,974)$ \\
\hline & $31.2 \%$ & $34.3 \%$ & $32.5 \%$ & $41.9 \%$ & $40.5 \%$ & $41.3 \%$ \\
\hline Household wealth quintile & & & $(N=13,140)$ & & & $(N=10,175)$ \\
\hline 1 - Lower & $15.7 \%$ & $20.0 \%$ & 17.4 & $19.5 \%$ & $23.3 \%$ & $21.0 \%$ \\
\hline 2 & $17.6 \%$ & $19.0 \%$ & 18.2 & $18.4 \%$ & $21.7 \%$ & $19.7 \%$ \\
\hline 3 & $19.7 \%$ & $17.9 \%$ & 19.0 & $20.1 \%$ & $19.7 \%$ & $19.9 \%$ \\
\hline 4 & $23.5 \%$ & $22.3 \%$ & 23.0 & $21.1 \%$ & $17.5 \%$ & $19.7 \%$ \\
\hline 5 - Higher & $23.5 \%$ & $20.8 \%$ & 22.4 & $20.9 \%$ & $17.8 \%$ & $19.7 \%$ \\
\hline Smoking status, & & & $(N=12,674)$ & & & $(N=10,629)$ \\
\hline Never & $47.4 \%$ & $51.4 \%$ & $48.9 \%$ & $44.0 \%$ & $44.2 \%$ & $44.0 \%$ \\
\hline Former smoker & $31.7 \%$ & $25.1 \%$ & $29.3 \%$ & $39.8 \%$ & $30.1 \%$ & $36.9 \%$ \\
\hline Current & $20.9 \%$ & $23.5 \%$ & $21.8 \%$ & $16.2 \%$ & $25.7 \%$ & $19.1 \%$ \\
\hline \multirow[t]{2}{*}{ Current alcohol consumption } & & & $(N=13,541)$ & & & $(N=13,008)$ \\
\hline & $57.2 \%$ & $56.8 \%$ & $57.1 \%$ & $55.5 \%$ & $56.0 \%$ & $55.7 \%$ \\
\hline \multirow[t]{2}{*}{ Engaged in vigorous exercise } & & & $(N=13,545)$ & & & $(N=11,901)$ \\
\hline & $25.6 \%$ & $38.7 \%$ & $30.7 \%$ & $21.4 \%$ & $33.7 \%$ & $26.3 \%$ \\
\hline \multirow[t]{2}{*}{ Low level of energy/Fatigue } & & & $(N=13,413)$ & & & $(N=13,545)$ \\
\hline & $25.7 \%$ & $34.0 \%$ & $28.9 \%$ & $21.6 \%$ & $43.8 \%$ & $30.3 \%$ \\
\hline \multirow[t]{2}{*}{ Sleep problems } & & & $(N=13,430)$ & & & $(N=13,545)$ \\
\hline & $24.8 \%$ & $35.9 \%$ & $29.1 \%$ & $25.8 \%$ & $45.1 \%$ & $33.3 \%$ \\
\hline \multirow[t]{2}{*}{ Difficulty walking by yourself } & & & $(N=12,972)$ & & & $(N=13,545)$ \\
\hline & $8.4 \%$ & $11.6 \%$ & $9.7 \%$ & $14.1 \%$ & $25.9 \%$ & $18.7 \%$ \\
\hline Self-reported health & & & $(N=12,818)$ & & & $(N=13,545)$ \\
\hline Poor & $3.5 \%$ & $7.5 \%$ & $5.1 \%$ & $4.8 \%$ & $15.1 \%$ & $8.9 \%$ \\
\hline Average/Fair/Moderate & $19.6 \%$ & $27.2 \%$ & $22.6 \%$ & $21.7 \%$ & $34.6 \%$ & $26.7 \%$ \\
\hline Good & $76.9 \%$ & $65.3 \%$ & $72.3 \%$ & $73.5 \%$ & $50.3 \%$ & $64.4 \%$ \\
\hline \multirow[t]{2}{*}{ Recent falls } & & & $(N=9656)$ & & & $(N=10,092)$ \\
\hline & $26.2 \%$ & $64.6 \%$ & $42.4 \%$ & $30.7 \%$ & $68.2 \%$ & $46.3 \%$ \\
\hline Evaluative wellbeing, & & & $(N=7178)$ & & & $(N=9467)$ \\
\hline
\end{tabular}


Table 1 Final regression model sample description (Continued)

\begin{tabular}{|c|c|c|c|c|c|c|}
\hline & Baseline & & & Follow-up & & \\
\hline & $\begin{array}{l}\text { No pain at } \\
\text { follow-up } \\
(N=8197)\end{array}$ & $\begin{array}{l}\text { Pain at } \\
\text { follow-up } \\
(N=5348)\end{array}$ & $\begin{array}{l}\text { Total } \\
(N=13,545)\end{array}$ & $\begin{array}{l}\text { No pain at } \\
\text { follow-up } \\
(N=8197)\end{array}$ & $\begin{array}{l}\text { Pain at follow-up } \\
(N=5348)\end{array}$ & $\begin{array}{l}\text { Total } \\
(N=13,545)\end{array}$ \\
\hline Low & $5.7 \%$ & $22.2 \%$ & $14.4 \%$ & $6.3 \%$ & $25.0 \%$ & $15.2 \%$ \\
\hline Middle & $20.8 \%$ & $27.9 \%$ & $24.5 \%$ & $18.6 \%$ & $28.2 \%$ & $23.2 \%$ \\
\hline High & $73.5 \%$ & $49.9 \%$ & $61.1 \%$ & $75.1 \%$ & $46.8 \%$ & $61.6 \%$ \\
\hline Diabetes & & & $(N=11,928)$ & & & $(N=12,214)$ \\
\hline & $11.8 \%$ & $15.7 \%$ & $13.1 \%$ & $19.0 \%$ & $19.6 \%$ & $19.2 \%$ \\
\hline Respiratory diseases & & & $(N=13,531)$ & & & $(N=12,084)$ \\
\hline & $8.0 \%$ & $9.2 \%$ & $8.5 \%$ & $10.7 \%$ & $14.0 \%$ & $12.0 \%$ \\
\hline Hypertension & & & $(N=13,527)$ & & & $(N=12,609)$ \\
\hline & $37.5 \%$ & $37.4 \%$ & $37.4 \%$ & $50.8 \%$ & $52.8 \%$ & $51.6 \%$ \\
\hline Joint disorders & & & $(N=13,537)$ & & & $(N=12,688)$ \\
\hline & $26.6 \%$ & $26.7 \%$ & $26.6 \%$ & $347 \%$ & $44.4 \%$ & $38.6 \%$ \\
\hline Angina & & & $(N=3453)$ & & & $(N=3453)$ \\
\hline & $1.5 \%$ & $2.2 \%$ & $1.7 \%$ & $2.8 \%$ & $4.5 \%$ & $3.4 \%$ \\
\hline Stroke & & & $(N=13,535)$ & & & $(N=12,084)$ \\
\hline & $1.1 \%$ & $1.9 \%$ & $1.4 \%$ & $1.7 \%$ & $2.7 \%$ & $2.1 \%$ \\
\hline Cancer & & & $(N=11,922)$ & & & $(N=11,503)$ \\
\hline & $1.7 \%$ & $3.2 \%$ & $2.3 \%$ & $2.3 \%$ & $4.6 \%$ & $3.2 \%$ \\
\hline Multimorbidity & & & $(N=13,544)$ & & & $(N=13,096)$ \\
\hline & $27.6 \%$ & $27.0 \%$ & $27.3 \%$ & $38.4 \%$ & $42.6 \%$ & $40.1 \%$ \\
\hline Obesity & & & $(N=13,545)$ & & & $(N=11,245)$ \\
\hline & $19.0 \%$ & $23.1 \%$ & $20.6 \%$ & $21.2 \%$ & $24.5 \%$ & $22.5 \%$ \\
\hline Depression & & & $(N=13,302)$ & & & $(N=13,451)$ \\
\hline & $10.6 \%$ & $22.3 \%$ & $15.2 \%$ & $10.6 \%$ & $29.8 \%$ & $18.1 \%$ \\
\hline Experience of a loss of any close person (bereavement) & & & $(N=13,545)$ & & & $(N=13,536)$ \\
\hline & $28.6 \%$ & $44.5 \%$ & $34.8 \%$ & $33.4 \%$ & $58.3 \%$ & $43.1 \%$ \\
\hline
\end{tabular}

cytokines in producing a hyperalgesic state. Excess of adipose tissue may in fact lead to an increased inflammatory response with through different chemical mediators involved in inflammation. Parallel to this, obesity determines increased risk and severity of musculoskeletal conditions, such as back pain [58]. In fact, the overload over low back, hip and knee joints cause injury and degradation to the cartilage and bone matrix in these structures, leading to osteoarthritis. In addition to this, known comorbidities of obesity that might exacerbate pain have to be taken into account, in particular sleep disorders (e.g. obstructive sleep apnoea) and depression [57, 59-61]. Evidence exist that weight loss programs, which include diet therapy and physical activity or, in specific cases, bariatric surgery, have positive effect on pain reduction in patients with different types of chronic musculoskeletal pain [62], osteoarthritis [63], back and knee pain [64], and migraine [65], and it showed to reduce up to $50 \%$ the risk of developing osteoarthritis on a 10-year period [66].

Exercising is protective for health in general, as also stated in the recent consensus statement on physical activity and ageing [67] where, however, an explicit mention to the fact that benefits for health among older adults can be realised at lower volumes and intensity than with the usually recommended " 150 min of moderate to vigorous intensity physical activity per week" is made. Besides exposing people to a higher risk of sportrelated injuries, moderate to vigorous exercise is predictive of the onset of back pain among ageing populations $[58,68]$, worsening of osteoarthritis-related pain severity [69]. Therefore, older adults and aging population should engage in mild to moderate, rather than vigorous, exercise.

Pain and fatigue have been found to be connected in several conditions, in particular musculoskeletal 
Table 2 Hierarchical pain predictive models: stepwise-selected baseline predictors, significant baseline predictors only $(p<0.05)$, significant baseline predictors and stepwise-selected follow-up predictors

\begin{tabular}{|c|c|c|c|c|c|c|}
\hline & \multicolumn{2}{|c|}{$\begin{array}{l}\text { Model 1: stepwise-selected } \\
\text { baseline predictors } \\
(N=16,097)\end{array}$} & \multicolumn{2}{|c|}{$\begin{array}{l}\text { Model 2: baseline with } \\
\text { significant predictors only } \\
(N=16,979)\end{array}$} & \multicolumn{2}{|c|}{$\begin{array}{l}\text { Model 3: significant baseline } \\
\text { predictors and stepwise- } \\
\text { selected follow-up predictors } \\
(N=11,852)\end{array}$} \\
\hline & OR $(95 \% \mathrm{Cl})$ & Z ( $p$-value) & OR $(95 \% \mathrm{Cl})$ & Z (p-value) & OR $(95 \% \mathrm{Cl})$ & Z (p-value) \\
\hline \multicolumn{7}{|l|}{ Baseline Variables } \\
\hline Female gender & $1.39(1.24-1.56)$ & $5.51(<.001)$ & $1.42(1.28-1.58)$ & $6.49(<.001)$ & $1.36(1.18-1.56)$ & $4.34(<.001)$ \\
\hline Engage in vigorous exercise & $1.50(1.32-1.71)$ & $6.10(<.001)$ & $1.73(1.53-1.95)$ & $8.93(<.001)$ & $3.10(2.64-3.64)$ & $13.69(<.001)$ \\
\hline Bereavement & $1.31(1.17-1.46)$ & $4.59(<.001)$ & $1.50(1.35-1.67)$ & $7.44(<.001)$ & $1.90(1.64-2.20)$ & $8.52(<.001)$ \\
\hline Obesity & $1.23(1.09-1.38)$ & $3.45(.001)$ & $1.22(1.09-1.36)$ & $3.37(<.001)$ & $1.17(1.00-1.36)$ & $1.97(.049)$ \\
\hline Self-rated health - average to moderate (vs. good) & $1.65(1.44-1.89)$ & $7.23(<.001)$ & $1.75(1.54-1.99)$ & $8.64(<.001)$ & $1.07(0.89-1.28)$ & $0.68(.499)$ \\
\hline Self-rated health - poor (vs. good) & $2.24(1.78-2.81)$ & $6.97(<.001)$ & $2.26(1.82-2.81)$ & $7.35(<.001)$ & $0.95(0.61-1.48)$ & $-0.23(.819)$ \\
\hline Sleep problems & $1.35(1.21-1.52)$ & $5.13(<.001)$ & $1.41(1.26-1.57)$ & $5.98(<.001)$ & $1.25(1.07-1.46)$ & $2.78(.005)$ \\
\hline Multimorbidity & $1.10(0.98-1.24)$ & $1.60(.109)$ & - & - & - & - \\
\hline Smoking - Former smoker (vs. never smoker) & $0.87(0.77-1.00)$ & $-2.02(.043)$ & - & - & - & - \\
\hline Smoking - Current smoker (vs. never smoker) & $1.15(0.98-1.24)$ & $1.91(.056)$ & - & - & - & - \\
\hline \multicolumn{7}{|l|}{ Follow-up Variables } \\
\hline Low energy level/Fatigue & & & & & $1.97(1.67-2.32)$ & $8.15(<.001)$ \\
\hline Self-rated health - average to moderate (vs. good) & & & & & $2.32(1.94-2.78$ & $9.19(<.001)$ \\
\hline Self-rated health - poor (vs. good) & & & & & $3.80(2.57-5.60)$ & $6.71(<.001)$ \\
\hline Difficulties with walking & & & & & $1.52(1.26-1.83)$ & $4.35(<.001)$ \\
\hline Sleep problems & & & & & $1.88(1.61-2.18)$ & $8.13(<.001)$ \\
\hline Respiratory disease & & & & & $1.26(1.03-1.56)$ & $2.19(.028)$ \\
\hline Joint disorders & & & & & $0.96(0.83-1.11)$ & $-0.57(.571)$ \\
\hline Stroke & & & & & $0.90(0.54-1.52)$ & $-0.38(.702)$ \\
\hline
\end{tabular}

Notes. Model 1: Hosmer-Lemeshow's $p$-value $=.085 ;$ AUC 0.64 (95\% Cl: 0.63-0.65). Model 2: Hosmer-Lemeshow's $p$-value $=.038 ;$ AUC 0.65 (95\% Cl: 0.64-0.66). Model 3: Hosmer-Lemeshow's $p$-value $=.010$; AUC $0.79(95 \% \mathrm{Cl}: 0.78-0.80)$

Table 3 Final hierarchical pain predictive model

\begin{tabular}{|c|c|c|}
\hline & \multicolumn{2}{|c|}{$\begin{array}{l}\text { Model 4: significant baseline and follow-up predictors } \\
(N=13,545)\end{array}$} \\
\hline & OR $(95 \% \mathrm{Cl})$ & Z (p-value) \\
\hline \multicolumn{3}{|l|}{ Baseline Variables } \\
\hline Female gender & $1.34(1.18-1.51)$ & $4.61(<.001)$ \\
\hline Engage in vigorous exercise & $2.51(2.18-2.89)$ & $12.71(<.001)$ \\
\hline Bereavement & $1.88(1.65-2.15)$ & $9.39(<.001)$ \\
\hline Obesity & $1.36(1.18-1.57)$ & $4.20(<.001)$ \\
\hline \multicolumn{3}{|l|}{ Follow-up Variables } \\
\hline Low energy level/Fatigue & $1.93(1.68-2.20)$ & $9.27(<.001)$ \\
\hline Self-rated health - average to moderate (vs. good) & $1.57(1.36-1.82)$ & $6.04(<.001)$ \\
\hline Self-rated health - poor (vs. good) & $2.20(1.71-2.83)$ & $6.13(<.001)$ \\
\hline Difficulties with walking & $1.69(1.43-1.99)$ & $6.12(<.001)$ \\
\hline Sleep problems & $1.80(1.58-2.05)$ & $8.97(<.001)$ \\
\hline
\end{tabular}


disorders such as rheumatoid arthritis and neuromuscular disorders such as fibromyalgia and chronic fatigue syndrome, and it is besides associated to poor sleep and symptoms of anxiety and depression [70-73]. However, the way in which fatigue exerts its effect on pain is unclear, but some hypotheses have been postulated, which include a common pathway mediated by inflammatory processes, such as increased levels of pro-inflammatory cytokines, and sensitisation of muscle nociceptors [72, 74]. Treatment strategy for fatigue include nutraceuticals, although with conflicting results [75-77], and exercise therapy [78].

Walking difficulties can be the outcome of several health problems - such as stroke, obesity or osteoarthritis - and thus require disease-specific treatments. For example, in post-stroke patients gait difficulties are very common and generally due to impairments in muscle strength, muscle tone, control over voluntary movement and balance, which result in reduced walking speed, temporal and spatial inter-limb asymmetries or impaired balance control [79]. Therefore, approaches to gait and walking rehabilitation in stroke survivors will need to address different impairments, making it really a patientspecific treatment. Among obese subjects, walking impairments are often due to knee osteoarthritis [80] and respiratory impairment or comorbidities [81, 82], and rehabilitation programmes for obesity reduction include moderate exercise aimed to improve walking, with positive effect on pain outcomes [62-64].

Conversely, our final model did not include some risk factors that have been found in previous literature, including sociodemographic data such as education and unemployment $[35,36]$, risk factors such as smoking [44], and health condition such as depression, diabetes, stroke, musculoskeletal diseases and multimorbidity status $[6,26,28-30,32,34,35,39-$ 41]. Some of them, namely smoking status vs. never smoking, multimorbidity, joint disorders or stroke, were included in the model, but not retained when other variables were included or when the final model with significant predictors only was run. The reason for this lack of predictive power is likely due to the large amount of variable we used, most of which were significantly associated in univariable analyses (see Table S2 in supplementary materials). A separate note has to be made for depression which was not selected from the stepwise logistic regression. Our data showed in fact that bereavement, i.e. the loss of a close person, was predictive of pain over a five-year period, whereas depression was not. Some studies showed that in some bereaved individuals the death of a loved one precipitates a combination of symptoms of both grief and depression, as well as of traumatic stress, although the categories are not overlapping [83-85], and depression was found in $18 \%$ to $55 \%$ of bereaved people [86-88]. Our hypothesis is that in a sample of ageing population like the one we analysed - where one-third of participants at baseline reported the experience of the loss of a close person, and $15 \%$ reported depression - the experience of bereavement confounded and overcame the predictive power of depression towards pain prediction. In addition to this, have no indication on the amount of time that passed between the loss experience and the interview, and on the presence of a problematic grief among bereaved people in our sample.

Some limitations have to be acknowledged. First, the variables used for our analysis are from a harmonized dataset, with a clear simplification from their original formulation. The main outcome definition is "self-reported pain experienced at the time of the interview", with a dichotomous output, and, for most of the studies herein used, the original items addressed pain in terms of severity and impact of pain, which spans between mild and disabling. Another variable for which relevant differences exist is "energy level" which in some studies (e.g. COURAGE in Europe) was addressed in terms of the amount of energy the person had (with response options varying between "not at all" and "completely") [89], whereas other studies (e.g. CHARLS) addressed it in terms of fatigue or "feeling that everything is an effort" (with response options based on frequency, from "rarely" to "most or all of the time") [90]. Second, there is a considerable variation in the lag between waves across studies, which varied between 2 and 11 years: we included the lag variable so to interpret predictors controlling for the difference between respondents' ageing across studies. Third, stepwise regression, which had the merit to enable reducing the amount of predictors to significant ones, present intrinsic problems, in particular biased high $\mathrm{R}^{2}$ values, small standard error and narrow 95\% CI for odd ratios, small and difficult to correct $p$-values due to multiple comparisons and exacerbated collinearity problems [91]. Fourth, when we selected the variables to be included in the models, we had to face the problems of variable missing values, which prevented some of them from being included (e.g. the variables "History of angina" and "Myocardial infarction or heart attack" had 51\% and $55 \%$ of missing, respectively, whereas "recent falls" which his intuitively of importance had $47 \%$ of missing). Possible solutions preserving to loose sample would have included treating them as a separate category by itself and data imputation. The problem with the first is that it would have led to biased estimation in regression coefficients. Imputation of missing values, e.g. through mean imputation or regression- 
based imputation, was not considered in reason of the very limited set of records, namely around 2000 out of the 50,849 not referring pain at baseline and with complete pain information at follow-up, with complete information for the remaining variables of interest: the reliability of a model with such a large amount of imputed values would have been at least debatable.

\section{Conclusions}

In conclusion, we showed that over a five-year period $39.5 \%$ of respondents from this ageing population that did not experience pain at baseline, developed pain at follow-up, and that there are distal and proximal risk factors for new pain onset. The first group included female gender, engaging in vigorous activities, being obese and suffering from the loss of a close person, whereas the second included low energy level (or fatigue), walking difficulties, self-rated health perceived as not good and sleep problems. Part of these predictors are directly modifiable: therefore, it is expectable that actions aimed at improving sleep, reducing weight among obese people and treating fatigue would positively impact on pain onset. In addition, indication to avoid vigorous exercise should also be provided to people aged around 60 years or older, in particular if female or obese.

\section{Supplementary information}

Supplementary information accompanies this paper at https://doi.org/10. 1186/s10194-020-01116-3.

\footnotetext{
Additional file 1: Table S1. Description of exploited studies and waves. Table S2. Univariable logistic regression results. Table S3. Multivariable logistic regression results. Table S4. Descriptive statistics, China Health and Retirement Longitudinal Study (CHARLS). Table S5. Descriptive statistics Collaborative Research on Ageing in Europe Study (COURAGE in Europe). Table S6. Descriptive statistics Health and Retirement Study (HRS). Table S7. Descriptive statistics Health 2000/2011 study (Health 2000/2011). Table S8. Descriptive statistics Mexican Health and Aging Study (MHAS). Table S9. Descriptive statistics Survey of Health, Ageing and Retirement in Europe (SHARE).
}

\section{Abbreviations \\ ATHLOS: Ageing Trajectories of Health - Longitudinal Opportunities and Synergies; AUC: Area Under the Receiver Operating Curve; BMI: Body Mass Index; CHARLS: China Health and Retirement Longitudinal Study; COURAGE in Europe: Collaborative Research on Ageing in Europe; HRS: Health and Retirement Study; IQR: Interquartile ranges; MHAS: Mexican Health and Aging Study; OR: Odds ratio; SHARE: Survey of Health, Ageing and Retirement in Europe; SD: Standard deviation; VIF: Variance Inflation Factor; 95\% Cl: 95\% Confidence Intervals}

\section{Acknowledgements}

The ATHLOS project researchers are grateful for data contribution and funding in the following studies:

- The China Health and Retirement Longitudinal Study (CHARLS): The CHARLS study has received critical support from Peking University, the National Natural Science Foundation of China, the Behavioral and Social Research Division of the National Institute on Aging and the World Bank. The authors gratefully acknowledge the work of the project team at the Peking University who provided data for this paper.
- Collaborative Research on Ageing (COURAGE) in Europe: The COURAGE study was supported by the European Community's Seventh Framework Programme (FP7/2007-2013) under grant agreement number 223071 (COURAGE in Europe). Data from Spain were also collected with support from the Instituto de Salud Carlos III-FIS research grants number PS09/00295, PS09/01845, PI12/01490, PI13/00059, PI16/00218 and PI16/01073; the Spanish Ministry of Science and Innovation ACl-Promociona (ACI2009-1010); the European Regional Development Fund (ERDF) 'A Way to Build Europe' grant numbers PI12/01490 and PI13/00059; and by the Centro de Investigación Biomédica en Red de Salud Mental (CIBERSAM), Instituto de Salud Carlos III. Data from Poland were collected with support from the Polish Ministry for Science and Higher Education grant for an international co-financed project (number 1277/7PR/UE/2009/7, 2009-2012) and Jagiellonian University Medical College grant for project COURAGE-POLFUS (K/ZDS/005241). The authors gratefully acknowledge the work of COURAGE researchers who provided data for this paper.

- The Health 2000/2011 study: The authors gratefully acknowledge the Finnish Institute for Health and Welfare who provided data for this paper. - Health and Retirement Study (HRS): The HRS study is supported by the National Institute on Aging (grant number NIA U01AG009740) and the Social Security Administration, and is conducted by the University of Michigan. The authors gratefully acknowledge the University of Michigan who provided data for this paper.

- The Mexican Health and Aging Study (MHAS): The MHAS study is partly sponsored by the National Institutes of Health/National Institute on Aging (grant number NIH R01AG018016) and the INEGI in Mexico. The authors gratefully acknowledge the MHAS team who provided data for this paper retrieved from www.MHASweb.org

- The Survey of Health, Ageing and Retirement in Europe (SHARE): The SHARE study is funded by the European Commission through FP5 (QLK6-CT2001-00360), FP6 (SHARE-I3: RII-CT-2006-062193, COMPARE: CIT5-CT-2005028857, SHARELIFE: CIT4-CT-2006-028812) and FP7 (SHARE-PREP: №211909, SHARE-LEAP: N²27822, SHARE M4: №261982). Additional funding from the German Ministry of Education and Research, the Max Planck Society for the Advancement of Science, the U.S. National Institute on Aging (U01_AG09740-13S2, P01_AG005842, P01_AG08291, P30_AG12815, R21_AG025169, Y1-AG-4553-01, IAG_BSR06-11, OGHA_04-064, HHSN271201300071C) and from various national funding sources is gratefully acknowledged (see www.share-project.org).

Alberto Raggi is supported by a grant from the Italian Ministry of Health (Ricerca Corrente, Fondazione Istituto Neurologico C. Besta, Linea 4-Outcome Research: dagli Indicatori alle Raccomandazioni Cliniche). Stefanos Tyrovolas was supported by the Foundation for Education and European Culture, the Miguel Servet programme (reference CP18/00006), and the Fondos Europeos de Desarrollo Regional.

\section{Authors' contributions}

AR, planned the analyses, drafted the manuscript and revised it for intellectual content; $M L$, planned the analyses and revised the manuscript for intellectual content; BMM, MVM, ASN, ST, IGV, JMH, SC, MB, JLAM, HA, SK, JB, $\mathrm{ZH}, \mathrm{BTA}$ and DP revised the manuscript for intellectual content; BC, planned and ran the analyses. The authors read and approved the final manuscript.

\section{Funding}

The ATHLOS project (Ageing Trajectories of Health: Longitudinal Opportunities and Synergies) has received funding from the European Union's Horizon 2020 research and innovation programme under grant agreement No 635316. The funding body had no role in the design of the study, analysis and interpretation of data, and in writing the manuscript.

\section{Availability of data and materials}

The datasets generated and/or analysed during the current study are not publicly available due restrictions imposed by part of the owners (COURAGE in Europe, the Health 2000 and 2011 Surveys- Finland), but may be available from the corresponding author upon reasonable request and once consent form ATHLOS project intellectual property and dissemination board is obtained.

\section{Ethics approval and consent to participate}

Not applicable for ATHLOS study: ethics approval and participants' consent to participate were obtained by each study at the time point of surveys' field trials. 


\section{Consent for publication}

Not applicable.

\section{Competing interests}

The authors declare that they have no competing interests.

\section{Author details}

${ }^{1}$ Neurology, Public Health and Disability Unit, Fondazione IRCCS Istituto Neurologico Carlo Besta, Via Celoria 11, 20133 Milan, Italy. ${ }^{2}$ Parc Sanitari Sant Joan de Déu, Fundacion Sant Joan de Deu, Barcelona, Spain. ${ }^{3}$ Instituto de Salud Carlos III, Centro de Investigación Biomédica en Red de Salud Mental, CIBERSAM, Madrid, Spain. ${ }^{4}$ Department of Nutrition and Dietetics, School of Health Science and Education, Harokopio University, Athens, Greece. ${ }^{5}$ Information, Evidence and Research, World Health Organization, Geneva, Switzerland. 'Research Department of Epidemiology and Public Health, University College London, London, UK. ${ }^{7}$ Department of Psychiatry, Universidad Autónoma de Madrid, Madrid, Spain. ${ }^{8}$ Hospital Universitario de La Princesa, Instituto de Investigación Sanitaria Princesa, Madrid, Spain. ${ }^{9}$ SPRING TECHNO GMBH \& Co. KG, Bremen, Germany. ${ }^{10}$ Department of Global Public Health, Karolinska Institute, Stockholm, Sweden. ${ }^{11}$ Department of Health Sciences and Health Policy, University of Lucerne, Lucerne, Switzerland. ${ }^{12}$ Swiss Paraplegic Research, Nottwil, Switzerland. ${ }^{13}$ Finnish Institute for Health and Welfare (THL), Helsinki, Finland. ${ }^{14}$ Department of Epidemiology and Population Studies, Faculty of Health Sciences, Jagiellonian University Medical College, Krakow, Poland. ${ }^{15}$ National Research Council, Neuroscience Institute, Padova, Italy.

Received: 13 April 2020 Accepted: 24 April 2020

Published online: 06 May 2020

\section{References}

1. Failde I, Dueñas M, Ribera MV, Gálvez R, Mico JA, Salazar A, de Sola H, Pérez C (2018) Prevalence of central and peripheral neuropathic pain in patients attending pain clinics in Spain: factors related to intensity of pain and quality of life. J Pain Res 11:1835-1847

2. Chenaf C, Delorme J, Delage N, Ardid D, Eschalier A, Authier N (2018) Prevalence of chronic pain with or without neuropathic characteristics in France using the capture-recapture method: a population-based study. Pain. 159:2394-2402

3. French HP, Smart KM, Doyle F (2017) Prevalence of neuropathic pain in knee or hip osteoarthritis: a systematic review and meta-analysis. Semin Arthritis Rheum 47:1-8

4. Mansfield KE, Sim J, Jordan JL, Jordan KP (2016) A systematic review and meta-analysis of the prevalence of chronic widespread pain in the general population. Pain. 157:55-64

5. Burch RC, Loder S, Loder E, Smitherman TA (2015) The prevalence and burden of migraine and severe headache in the United States: updated statistics from government health surveillance studies. Headache. 55:21-34

6. Mundal I, Gråwe RW, Bjørngaard JH, Linaker OM, Fors EA (2014) Prevalence and long-term predictors of persistent chronic widespread pain in the general population in an 11-year prospective study: the HUNT study. BMC Musculoskelet Disord 15:213

7. Straube A, Aicher B, Förderreuther S, Eggert T, Köppel J, Möller S, Schneider R, Haag G (2013) Period prevalence of self-reported headache in the general population in Germany from 1995-2005 and 2009: results from annual nationwide population-based cross-sectional surveys. J Headache Pain. 14:11

8. Vivekanantham A, Edwin C, Pincus T, Matharu M, Parsons H, Underwood M (2019) The association between headache and low back pain: a systematic review. J Headache Pain. 20(1):82

9. Stovner LJ, Andree C (2010) Prevalence of headache in Europe: a review for the Eurolight project. J Headache Pain. 11:289-299

10. Linde M, Stovner LJ, Zwart JA, Hagen K (2011) Time trends in the prevalence of headache disorders. The Nord-Trondelag health studies (HUNT 2 and HUNT 3). Cephalalgia. 31:585-596

11. Lj S, Hagen K, Jensen R, Katsarava Z, Lipton R, Scher A, Steiner T, Zwart JA (2007) The global burden of headache: a documentation of headache prevalence and disability worldwide. Cephalalgia. 27:193-210

12. Nahin RL, Sayer B, Stussman BJ, Feinberg TM (2019) Eighteen-year trends in the prevalence of, and health care use for, noncancer pain in the United States: data from the medical expenditure panel survey. J Pain 20:796-809
13. Sanchez-Niubo A, Egea-Cortés L, Olaya B, Caballero FF, Ayuso-Mateos JL, Prina M, Bobak M, Arndt H, Tobiasz-Adamczyk B, Pająk A, Leonardi M, Koupil I, Panagiotakos D, Tamosiunas A, Scherbov S, Sanderson W, Koskinen S, Chatterji S, Haro JM (2019) ATHLOS Consortium. Cohort profile: the ageing trajectories of health - longitudinal opportunities and synergies (ATHLOS) project. Int J Epidemiol 48:1052-1053i

14. Guido D, Leonardi M, Mellor B, Moneta MV, Sanchez-Niubo A, Tyrovolas S, Giné-Vázquez I, Haro JM, Chatterji S, Bobak M, Ayuso-Mateos JL, Arndt H, Koupil I, Bickenbach J, Koskinen S, Tobiasz-Adamczyk B, Panagiotakos D, Raggi A (2020) Pain rates in general population for the period 1991-2015 and 10-years prediction: results from a multi-continent age-period-cohort analysis. J Headache Pain. https://doi.org/10.1186/s10194-020-01108-3.

15. Harrison JM, Lagisetty P, Sites BD, Guo C, Davis MA (2018) Trends in prescription pain medication use by race/ethnicity among us adults with noncancer pain, 2000-2015. Am J Public Health 108:788-790

16. Negro A, Sciattella P, Rossi D, Guglielmetti M, Martelletti P, Mennini FS (2019) Cost of chronic and episodic migraine patients in continuous treatment for two years in a tertiary level headache Centre. J Headache Pain 20(1):120

17. Ropponen A, Narusyte J, Mittendorfer-Rutz E, Svedberg P (2019) Number of pain locations as predictor of cause-specific disability pension in Swedendo common mental disorders play a role? J Occup Environ Med 61:646-652

18. Raggi A, Corso B, De Torres L, Quintas R, Chatterji S, Sainio P, Martinuzzi A, Zawisza K, Haro JM, Minicuci N, Leonardi M (2018) Determinants of mobility in populations of older adults: results from a cross-sectional study in Finland, Poland and Spain. Maturitas 115:84-91

19. Raggi A, Corso B, Minicuci N, Quintas R, Sattin D, De Torres L, Chatterji S, Frisoni GB, Haro JM, Koskinen S, Martinuzzi A, Miret M, Tobiasz-Adamczyk B, Leonardi M (2016) Determinants of quality of life in ageing populations: results from a cross-sectional study in Finland, Poland and Spain. PLoS One 11:e0159293

20. Husky MM, Ferdous Farin F, Compagnone P, Fermanian C, Kovess-Masfety V (2018) Chronic back pain and its association with quality of life in a large French population survey. Health Qual Life Outcomes 16:195

21. Abu Bakar N, Tanprawate S, Lambru G, Torkamani M, Jahanshahi M, Matharu M (2016) Quality of life in primary headache disorders: a review. Cephalalgia. 36:67-91

22. Bernfort L, Gerdle B, Rahmqvist M, Husberg M, Levin LÅ (2015) Severity of chronic pain in an elderly population in Sweden--impact on costs and quality of life. Pain. 156:521-527

23. Lantéri-Minet M, Duru G, Mudge M, Cottrell S (2011) Quality of life impairment, disability and economic burden associated with chronic daily headache, focusing on chronic migraine with or without medication overuse: a systematic review. Cephalalgia. 31:837-850

24. de Sola H, Salazar A, Dueñas M, Ojeda B, Failde I (2016) Nationwide crosssectional study of the impact of chronic pain on an individual's employment: relationship with the family and the social support. BMJ Open 6:e012246

25. Selekler HM, Gökmen G, Alvur TM, Steiner TJ (2015) Productivity losses attributable to headache, and their attempted recovery, in a heavymanufacturing workforce in Turkey: implications for employers and politicians. J Headache Pain. 16:96

26. Larsson B, Dragioti E, Grimby-Ekman A, Gerdle B, Björk J (2019) Predictors of chronic pain intensity, spread, and sensitivity in the general population: a two-year follow-up study from the SWEPAIN cohort. J Rehabil Med 51:183-192

27. Hofstede SN, Gademan MGJ, Stijnen T, Nelissen RGHH, Marang-van de Mheen PJ, ARGON-OPTIMA study group (2018) The influence of preoperative determinants on quality of life, functioning and pain after total knee and hip replacement: a pooled analysis of Dutch cohorts. BMC Musculoskelet Disord 19:68

28. Liu XK, Xiao SY, Zhou L, Hu M, Liu HM (2018) Different predictors of pain severity across age and gender of a Chinese rural population: a crosssectional survey. BMJ Open 8:e020938

29. Brady SRE, Monira Hussain S, Brown WJ, Heritier S, Wang Y, Teede H, Urquhart DM, Cicuttini FM (2017) Predictors of back pain in middle-aged women: data from the Australian Longitudinal Study of Women's Health. Arthritis Care Res (Hoboken) 69:709-716

30. Elsharydah A, Loo NH, Minhajuddin A, Kandil ES (2017) Complex regional pain syndrome type 1 predictors - epidemiological perspective from a national database analysis. J Clin Anesth 39:34-37 
31. Neupane S, Nygård CH, Oakman J (2016) Work-related determinants of multi-site musculoskeletal pain among employees in the health care sector. Work. 54:689-697

32. Butler S, Jonzon B, Branting-Ekenbäck C, Wadell C, Farahmand B (2013) Predictors of severe pain in a cohort of 5271 individuals with self-reported neuropathic pain. Pain. 154:141-146

33. George SZ, Childs JD, Teyhen DS, Wu SS, Wright AC, Dugan JL, Robinson ME (2012) Predictors of occurrence and severity of first time low back pain episodes: findings from a military inception cohort. PLoS One 7:e30597

34. McBeth J, Lacey RJ, Wilkie R (2014) Predictors of new-onset widespread pain in older adults: results from a population-based prospective cohort study in the UK. Arthritis Rheumatol 66:757-767

35. Pan F, Tian J, Aitken D, Cicuttini F, Jones G (2018) Predictors of pain severity trajectory in older adults: a 10.7-year follow-up study. Osteoarthr Cartil 26: 1619-1626

36. Großschädl F, Stolz E, Mayerl H, Rásky É, Freidl W, Stronegger W (2016) Educational inequality as a predictor of rising back pain prevalence in Austria-sex differences. Eur J Pub Health 26:248-253

37. Chen Y, Campbell P, Strauss WY, Foster NE, Jordan KP, Dunn KM (2018) Trajectories and predictors of the long-term course of low back pain: cohort study with 5-year follow-up. Pain. 159:252-260

38. Aili K, Andersson M, Bremander A, Haglund E, Larsson I, Bergman S (2018) Sleep problems and fatigue as predictors for the onset of chronic widespread pain over a 5- and 18-year perspective. BMC Musculoskelet Disord 19:390

39. Christensen JO, Johansen S, Knardahl S (2017) Psychological predictors of change in the number of musculoskeletal pain sites among Norwegian employees: a prospective study. BMC Musculoskelet Disord 18:140

40. Helminen EE, Sinikallio SH, Valjakka AL, Väisänen-Rouvali RH, Arokoski JP (2016) Determinants of pain and functioning in knee osteoarthritis: a oneyear prospective study. Clin Rehabil 30:890-900

41. Udom C, Kanlayanaphotporn R, Janwantanakul P (2019) Predictors for nonspecific low back pain in rubber farmers: a 1-year prospective cohort study. Asia Pac J Public Health 31:7-17

42. Klit H, Finnerup NB, Overvad K, Andersen G, Jensen TS (2011) Pain following stroke: a population-based follow-up study. PLoS One 6:e27607

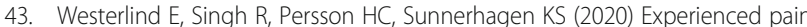
after stroke: a cross-sectional 5-year follow-up study. BMC Neurol 20:4

44. Holley AL, Law EF, Tham SW, Myaing M, Noonan C, Strachan E, Palermo TM (2013) Current smoking as a predictor of chronic musculoskeletal pain in young adult twins. J Pain 14:1131-1139

45. Sihawong R, Sitthipornvorakul E, Paksaichol A, Janwantanakul P (2016) Predictors for chronic neck and low back pain in office workers: a 1year prospective cohort study. J Occup Health 58:16-24

46. Braden JB, Young A, Sullivan MD, Walitt B, Lacroix AZ, Martin L (2012) Predictors of change in pain and physical functioning among postmenopausal women with recurrent pain conditions in the women's health initiative observational cohort. J Pain 13:64-72

47. Amiri S, Behnezhad S (2020; E-Pub on Mar 12) Sleep disturbances and back pain: Systematic review and meta-analysis. Neuropsychiatr. https://doi.org/ 10.1007/s40211-020-00339-9

48. Song TJ, Cho SJ, Kim WJ, Yang KI, Yun CH, Chu MK (2018) Poor sleep quality in migraine and probable migraine: a population study. J Headache Pain. 19:58

49. Pickering ME, Chapurlat R, Kocher L, Peter-Derex L (2016) Sleep disturbances and osteoarthritis. Pain Pract 16:237-244

50. Koffel E, McCurry SM, Smith MT, Vitiello MV (2019) Improving pain and sleep in middle-aged and older adults: the promise of behavioral sleep interventions. Pain. 160:529-534

51. Watkins LR, Maier SF (2000) The pain of being sick: implications of immune-tobrain communication for understanding pain. Annu Rev Psychol 51:29-57

52. Gulia KK, Kumar VM (2018) Sleep disorders in the elderly: a growing challenge. Psychogeriatrics. 18:155-165

53. Cheatle MD, Foster S, Pinkett A, Lesneski M, Qu D, Dhingra L (2016) Assessing and managing sleep disturbance in patients with chronic pain. Sleep Med Clin 11:531-541

54. Nijs J, Mairesse O, Neu D, Leysen L, Danneels L, Cagnie B, Meeus M, Moens M, Ickmans K, Goubert D (2018) Sleep disturbances in chronic pain: neurobiology, assessment, and treatment in physical therapist practice. Phys Ther 98:325-335

55. Schroeck JL, Ford J, Conway EL, Kurtzhalts KE, Gee ME, Vollmer KA, Mergenhagen KA (2016) Review of safety and efficacy of sleep medicines in older adults. Clin Ther 38:2340-2372
56. McVinnie DS (2013) Obesity and pain. Br J Pain 7:163-170

57. Okifuji A, Hare BD (2015) The association between chronic pain and obesity J Pain Res 8:399-408

58. Brady SRE, Hussain SM, Brown WJ, Heritier S, Wang Y, Teede H, Urquhart DM, Cicuttini FM (2018) Course and contributors to back pain in middleaged women over 9 years: data from the Australian Longitudinal Study on Women's Health. Spine (Phila Pa 1976) 43:1648-1656

59. Beccuti G, Pannain S (2011) Sleep and obesity. Curr Opin Clin Nutr Metab Care 14:402-412

60. Badran M, Ayas N, Laher I (2014) Insights into obstructive sleep apnea research. Sleep Med 15:485-495

61. Pratt LA, Brody DJ (2014) Depression and obesity in the US adult household population, 2005-2010. NCHS Data Brief 167:1-8

62. Cooper L, Ryan CG, Ells LJ, Hamilton S, Atkinson G, Cooper K, Johnson MI, Kirwan JP, Martin D (2018) Weight loss interventions for adults with overweight/obesity and chronic musculoskeletal pain: a mixed methods systematic review. Obes Rev 19:989-1007

63. Riddle DL, Stratford PW (2013) Body weight changes and corresponding changes in pain and function in persons withsymptomatic knee osteoarthritis: a cohort study. Arthritis Care Res (Hoboken) 65:15-22

64. Vincent HK, Ben-David K, Conrad BP, Lamb KM, Seay AN, Vincent KR (2012) Rapid changes in gait, musculoskeletal pain, and quality of life after bariatric surgery. Surg Obes Relat Dis 8:346-354

65. Di Vincenzo A, Beghetto M, Vettor R, Tana C, Rossato M, Bond DS, Pagano C (2020. Epub on February 1) Effects of surgical and non-surgical weight loss on migraine headache: a systematic review and meta-analysis. Obes Surg. https://doi.org/10.1007/s11695-020-04429-z

66. Felson DT, Zhang Y, Anthony JM, Naimark A, Anderson JJ (1992) Weight loss reduces the risk for symptomatic knee osteoarthritis in women. The Framingham Study. Ann Intern Med 116:535-539

67. Bangsbo J, Blackwell J, Boraxbekk CJ, Caserotti P, Dela F, Evans AB, Jespersen AP, Gliemann L, Kramer AF, Lundbye-Jensen J, Mortensen EL, Lassen AJ, Gow AJ, Harridge SDR, Hellsten Y, Kjaer M, Kujala UM, Rhodes RE, Pike ECJ, Skinner T, Skovgaard T, Troelsen J, Tulle E, Tully MA, van Uffelen JGZ, Viña J (2019) Copenhagen consensus statement 2019: physical activity and ageing. Br J Sports Med 53:856-858

68. Liu SH, Driban JB, Eaton CB, McAlindon TE, Harrold LR, Lapane KL (2016) Objectively measured physical activity and symptoms change in knee osteoarthritis. Am J Med 129:497-505 e1

69. Kim W, Jin YS, Lee CS, Hwang CJ, Lee SY, Chung SG, Choi KH (2014) Relationship between the type and amount of physical activity and low back pain in Koreans aged 50 years and older. PM R 6:893-899

70. Nikolaus S, Bode C, Taal E, van de Laar MA (2013) Fatigue and factors related to fatigue in rheumatoid arthritis: a systematic review. Arthritis Care Res (Hoboken) 65:1128-1246

71. van Dartel SA, Repping-Wuts JW, van Hoogmoed D, Bleijenberg G, van Riel PL, Fransen J (2013) Association between fatique and pain in rheumatoid arthritis: does pain precede fatigue or does fatigue precede pain? Arthritis Care Res (Hoboken) 65:862-869

72. Mastaglia FL (2012) The relationship between muscle pain and fatigue. Neuromuscul Disord 22(Suppl 3):S178-S180

73. Vincent A, Benzo RP, Whipple MO, McAllister SJ, Erwin PJ, Saligan LN (2013) Beyond pain in fibromyalgia: insights into the symptom of fatigue. Arthritis Res Ther 15:221

74. Louati K, Berenbaum F (2015) Fatigue in chronic inflammation - a link to pain pathways. Arthritis Res Ther. 17:254

75. Arring NM, Millstine D, Marks LA, Nail LM (2018) Ginseng as a treatment for fatigue: a systematic review. J Altern Complement Med 24:624-633

76. Bjørklund G, Dadar M, Pen JJ, Chirumbolo S, Aaseth J (2019) Chronic fatique syndrome (CFS): suggestions for a nutritional treatment in the therapeutic approach. Biomed Pharmacother 109:1000-1007

77. Wan JJ, Qin Z, Wang PY, Sun Y, Liu X (2017) Muscle fatigue: general understanding and treatment. Exp Mol Med 49:e384

78. Larun L, Brurberg KG, Odgaard-Jensen J, Price JR (2019) Exercise therapy for chronic fatigue syndrome. Cochrane Database Syst Rev 10:CD003200

79. Beyaert C, Vasa R, Frykberg GE (2015) Gait post-stroke: pathophysiology and rehabilitation strategies. Neurophysiol Clin 45(4-5):335-355

80. Yázigi F, Espanha M, Marques A, Teles J, Teixeira P (2018) Predictors of walking capacity in obese adults with knee osteoarthritis. Acta Reumato Port 43:256-263 
81. Ochs-Balcom HM, Grant BJ, Muti P, Sempos CT, Freudenheim JL, Trevisan M, Cassano PA, lacoviello L, Schünemann HJ (2006) Pulmonary function and abdominal adiposity in the general population. Chest 129:853-862

82. Yilmaz FT, Aydin HT (2018) The effect of a regular walking program on dyspnoea severity and quality of life in normal weight, overweight, and obese patients with chronic obstructive pulmonary disease. Int J Nurs Pract 24:e12636

83. Djelantik AAAMJ, Smid GE, Kleber RJ, Boelen PA (2017) Symptoms of prolonged grief, post-traumatic stress, and depression after loss in a Dutch community sample: a latent class analysis. Psychiatry Res 247:276-281

84. Boelen PA, Reijntjes A, AAAM JD, Smid GE (2016) Prolonged grief and depression after unnatural loss: Latent class analyses and cognitive correlates. Psychiatry Res 240:358-363

85. Nickerson A, Liddell BJ, Maccallum F, Steel Z, Silove D, Bryant RA (2014) Posttraumatic stress disorder and prolonged grief in refugees exposed to trauma and loss. BMC Psychiatry 14:106

86. Otani H, Yoshida S, Morita T, Aoyama M, Kizawa Y, Shima Y, Tsuneto S, Miyashita M (2017) Meaningful communication before death, but not present at the time of death itself, is associated with better outcomes on measures of depression and complicated grief among bereaved family members of cancer patients. J Pain Symptom Manag 54:273-279

87. Wikman A, Mattsson E, von Essen L, Hovén E (2018) Prevalence and predictors of symptoms of anxiety and depression, and comorbid symptoms of distress in parents of childhood cancer survivors and bereaved parents five years after end of treatment or a child's death. Acta Oncol 57:950-957

88. Allen JY, Haley WE, Small BJ, Schonwetter RS, McMillan SC (2013) Bereavement among hospice caregivers of cancer patients one year following loss: predictors of grief, complicated grief, and symptoms of depression. J Palliat Med 16:745-751

89. Leonardi M, Chatterji S, Koskinen S, Ayuso-Mateos JL, Haro JM, Frisoni G, Frattura L, Martinuzzi A, Tobiasz-Adamczyk B, Gmurek M, Serrano R, Finocchiaro C, COURAGE in Europe Project's Consortium (2014) Determinants of health and disability in ageing population: the COURAGE in Europe project (collaborative research on ageing in Europe). Clin Psychol Psychother 21:193-198

90. Zhao Y, Hu Y, Smith JP, Strauss J, Yang G (2014) Cohort profile: the China health and retirement longitudinal study (CHARLS). Int J Epidemiol 43:61-68

91. Harrell F (2015) Regression modelling strategies. Basel, Springer Nature Switzerland AG

\section{Publisher's Note}

Springer Nature remains neutral with regard to jurisdictional claims in published maps and institutional affiliations.

Ready to submit your research? Choose BMC and benefit from:

- fast, convenient online submission

- thorough peer review by experienced researchers in your field

- rapid publication on acceptance

- support for research data, including large and complex data types

- gold Open Access which fosters wider collaboration and increased citations

- maximum visibility for your research: over $100 \mathrm{M}$ website views per year

At BMC, research is always in progress.

Learn more biomedcentral.com/submissions 